\title{
Polymer Coated CaAl-Layered Double Hydroxide Nanomaterials for Potential Calcium Supplement
}

\author{
Tae-Hyun Kim ${ }^{1, \dagger}$, Jeong-A Lee ${ }^{2, \dagger}$, Soo-Jin Choi ${ }^{2, *}$ and Jae-Min Oh ${ }^{1, *}$ \\ 1 Department of Chemistry and Medical Chemistry, College of Science and Technology, \\ Yonsei University, Wonju, Gangwondo 220710, Korea; E-Mail: th.kim@yonsei.ac.kr \\ 2 Department of Food Science and Technology, Seoul Women's University, Seoul 139774, Korea; \\ E-Mail: junga0462@hanmail.net
}

$\dagger$ These authors contributed equally to this work.

* Authors to whom correspondence should be addressed;

E-Mails: sjchoi@swu.ac.kr (S.-J.C.); jaemin.oh@yonsei.ac.kr (J.-M.O.);

Tel.: +82-2-970-5634 (S.-J.C.); +82-33-760-2368 (J.-M.O.);

Fax: +82-2-970-5977 (S.-J.C.); +82-33-760-2182 (J.-M.O.).

External Editor: Bing Yan

Received: 31 October 2014; in revised form: 18 November 2014 / Accepted: 27 November 2014 / Published: 5 December 2014

\begin{abstract}
We have successfully prepared layered double hydroxide (LDH) nanomaterials containing calcium and aluminum ions in the framework (CaAl-LDH). The surface of CaAl-LDH was coated with enteric polymer, Eudragit ${ }^{\circledR} \mathrm{L} 100$ in order to protect nanomaterials from fast dissolution under gastric condition of $\mathrm{pH}$ 1.2. The X-ray diffraction patterns, Fourier transform infrared spectroscopy, scanning electron and transmission electron microscopy revealed that the pristine LDH was well prepared having hydrocalumite structure, and that the polymer effectively coated the surface of LDH without disturbing structure. From thermal analysis, it was determined that only a small amount (less than 1\%) of polymer was coated on the LDH surface. Metal dissolution from LDH nanomaterials was significantly reduced upon Eudragit ${ }^{\circledR} \mathrm{L} 100$ coating at $\mathrm{pH}$ 1.2, 6.8 and 7.4, which simulates gastric, enteric and plasma conditions, respectively, and the dissolution effect was the most suppressed at $\mathrm{pH}$ 1.2. The LDH nanomaterials did not exhibit any significant cytotoxicity up to $1000 \mu \mathrm{g} / \mathrm{mL}$ and intracellular calcium concentration significantly increased in LDH-treated human intestinal cells. Pharmacokinetic study demonstrated absorption efficiency of Eudragit ${ }^{\circledR}$ L 100 coated $\mathrm{LDH}$ following oral administration to rats. Moreover, the LDH
\end{abstract}


nanomaterials did not cause acute toxic effect in vivo. All the results suggest the great potential of CaAl-LDH nanomaterials as a calcium supplement.

Keywords: CaAl-LDH; polymer coating; pharmacokinetics; toxicity

\section{Introduction}

Along with the rapid development of nanotechnology in diverse industrial fields, nanomaterials have been also widely applied to bio-related products, such as medicine, medical devices, pharmaceutics, personal care products, food etc. to endow a novel physicochemical property, to enhance functionality, bioactivity and bioavailability, and to effectively deliver bioactive molecules to target specific organs [1-4]. Application of nanomaterials in human-related biological fields can be generally categorized into several sectors: (1) nanomedicines including drug delivery systems or diagnostics; (2) consumer products like UV-screening agents; (3) food additives such as anticaking and whitening agents or nutritional supplements to fortify absorption of nutrients [5-7]. Currently, most studies on nano-bio materials have been done in order to enhance stability and absorption of bioactive substances by encapsulating them in nanomaterials [8-12]. However, attempts on the development of functional nanomaterial itself as a nutritional supplement have not been extensively carried out.

Calcium is one of the essential inorganic elements in biological systems not only as a major constituent of skeletal systems, such as bone and teeth, but also as a mediator in various physiological functions [13-15]. It has been reported that the calcium deficiency results in serious diseases, such as osteoporosis and hypocalcaemia. Hence, various calcium supplements including calcium carbonate, calcium citrate, calcium phosphate and calcium gluconate have been developed [16]. Among them, calcium carbonate obtained from oyster shell is widely distributed on the market, because it is relatively inexpensive and abundant in nature [17]. However, it is generally known that oral bioavailability of calcium from calcium carbonate supplement is extremely low, approximately $4 \%$ [18].

As a potential candidate for calcium supplement nanomaterials, we developed layered double hydroxide (LDH) nanoparticle, a kind of layered mineral. LDHs are composed of positively charged mixed metal hydroxide layers and exchangeable interlayer anions. The general formula of LDHs is represented as follow: $\left[\mathrm{M}(\mathrm{II})_{1-\mathrm{x}} \mathrm{M}(\mathrm{III})_{\mathrm{x}}(\mathrm{OH})_{2}\right]^{\mathrm{x}+}\left(\mathrm{A}^{\mathrm{n}-}\right)_{\mathrm{x} / \mathrm{n}} \cdot \mathrm{mH}_{2} \mathrm{O}\left(\mathrm{M}\right.$ : divalent or trivalent metal ions, $\mathrm{A}^{\mathrm{n}-}$ : anionic species). Due to the diversity of exchangeable anions, intercalation capacity and biological inertness, LDHs have been explored as delivery nanovehicles for drugs and bioactive molecules $[19,20]$. Furthermore, LDHs have been reported to enhance cellular uptake rate as well as chemical/biological stability of intercalated biomolecules $[21,22]$. Calcium cations are known to readily dissolve in acidic and neutral $\mathrm{pH}$, and then form hydroxide precipitates in basic conditions. Thus, it is expected that calcium containing LDHs are expected to be dissolved into absorbable ions under gastric $(\mathrm{pH} 1.2)$ and small intestine ( $\mathrm{pH} \sim 6.8$ ) conditions. Incorporation of bioactive molecules into calcium containing LDHs further enables the development of a dual functional system having both calcium supplement and delivery functions.

In this paper, we prepared calcium containing LDH nanomaterials, CaAl-LDH, and the surface of calcium-containing LDH was then coated with enteric coating polymer, Eudragit ${ }^{\mathbb{R}} \mathrm{L} 100$ [23], aiming to facilitate efficient calcium dissolution and absorption in the small intestine [24]. The Eudragit ${ }^{\circledR} \mathrm{L} 100$ 
polymer consisting of methacryalate and metharcylic acid is known to flocculate at acidic $\mathrm{pH}$ and be solubilized at $\mathrm{pH}$ above $\sim 6.0$, an intestinal $\mathrm{pH}$ condition [25]. Hence, the Eudragit ${ }^{\circledR} \mathrm{L} 100$ coating can protect LDH from acidic gastric conditions, and also help to dissolve LDH in small intestine. Physicochemical properties and $\mathrm{pH}$-dependent solubility of Eudragit ${ }^{\circledR} \mathrm{L}$ 100-coated CaAl-LDH (E-coated CaAl-LDH) were characterized. Furthermore, its cellular calcium uptake, pharmacokinetics and in vitro and in vivo toxicity were evaluated.

\section{Results and Discussion}

The crystal structure of pristine CaAl-LDH was confirmed with powder X-ray diffraction (XRD) patterns (Figure 1). As the LDH consisted of the stacking of 2-dimensional metal hydroxide nanosheets along the $z$-axis, we observed intense (002) and (004) peaks in the diffraction patterns. We could assign the characteristic diffraction peaks of Ca-containing LDH to (112), (020) and (316) at 2-theta values of $23.4^{\circ}, 31.1^{\circ}$ and $38.9^{\circ}$ of hydrocalumite $\left(\mathrm{Ca}_{4} \mathrm{Al}_{2} \mathrm{O}_{6} \mathrm{Cl}_{2} \cdot 12 \mathrm{H}_{2} \mathrm{O}\right.$, JCPDS No 31-0245), respectively. The calculated lattice parameters, $\mathrm{a}_{0}$ and $\mathrm{c}_{0}$ of 11.51 and $17.10 \AA$, respectively, also reflected that the obtained pristine LDH has the expected structure as previously reported [26].

As the peak positions and patterns of E-coated CaAl-LDH were almost same to those of pristine LDH, we could confirm that the coating process was successfully carried out without disturbing the overall crystal structure of LDH. In order to investigate the crystallinity change of CaAl-LDH upon Eudragit ${ }^{\circledR} \mathrm{L}$ 100 coating, we calculated the crystallite sizes of samples based on Scherrer's equation (Equation (1)) [27] as to two major peaks, (002) and (020). Crystallite sizes of CaAl-LDH calculated from (002) and (020) peaks were 48.4 and $52.6 \mathrm{~nm}$, respectively, while those values of E-coated CaAl-LDH were 45.8 and $48.3 \mathrm{~nm}$, respectively. Accordingly, crystallite size was reduced by $\sim 5 \%$ and $\sim 8 \%$ in (002) and (020) direction during coating process. This decrement might be attributed to slight dissolution of pristine LDH during coating process. However, the degree of dissolution seems to be low to not cause remarkable loss of pristine LDH during the coating process.

$$
t=\frac{0.9 \lambda}{\beta \cos \theta}
$$

$t$ : crystallite size; $\lambda$ : X-ray wavelength of $1.5405 \AA ; \beta$ : Full width at half maximum of peak; $\theta$ : Bragg angle.

Surface coating of LDHs with Eudragit ${ }^{\circledR} \mathrm{L} 100$ was performed to protect them from acidic condition, not to modify their chemical structure. It is worth to note that we used ethanol rather than alkaline solution to solubilize Eudragit ${ }^{\circledR} \mathrm{L} 100$ for the coating process. The alkaline solution can solubilize Eudragit ${ }^{\circledR}$ L 100 through detaching protons from methacrylic acid residue, thereby inducing a negative charge at the polymer side chain. It was reported that the polymer could be intercalated into the interlayer space of layered materials when they possessed strong and periodic negative charge on the backbone, resulting in the formation of polymer-inorganic layer-by-layer hybrid structure or swelling of the layered structure [28-31]. Therefore, the methacrylic acid residues could be preserved in ethanol solution and gradually interact with the basic surface of LDHs. In this way, Eudragit ${ }^{\circledR}$ L 100 could coat homogeneously the LDH surface without intercalation. 
Figure 1. Powder XRD patterns for (a) pristine CaAl-LDH and (b) E-coated CaAl-LDH; (c) Crystal structure of CaAl-LDH (hydrocalumite, JCPDS No. 31-0245) and (d) schematic illustration of E-coated CaAl-LDH.

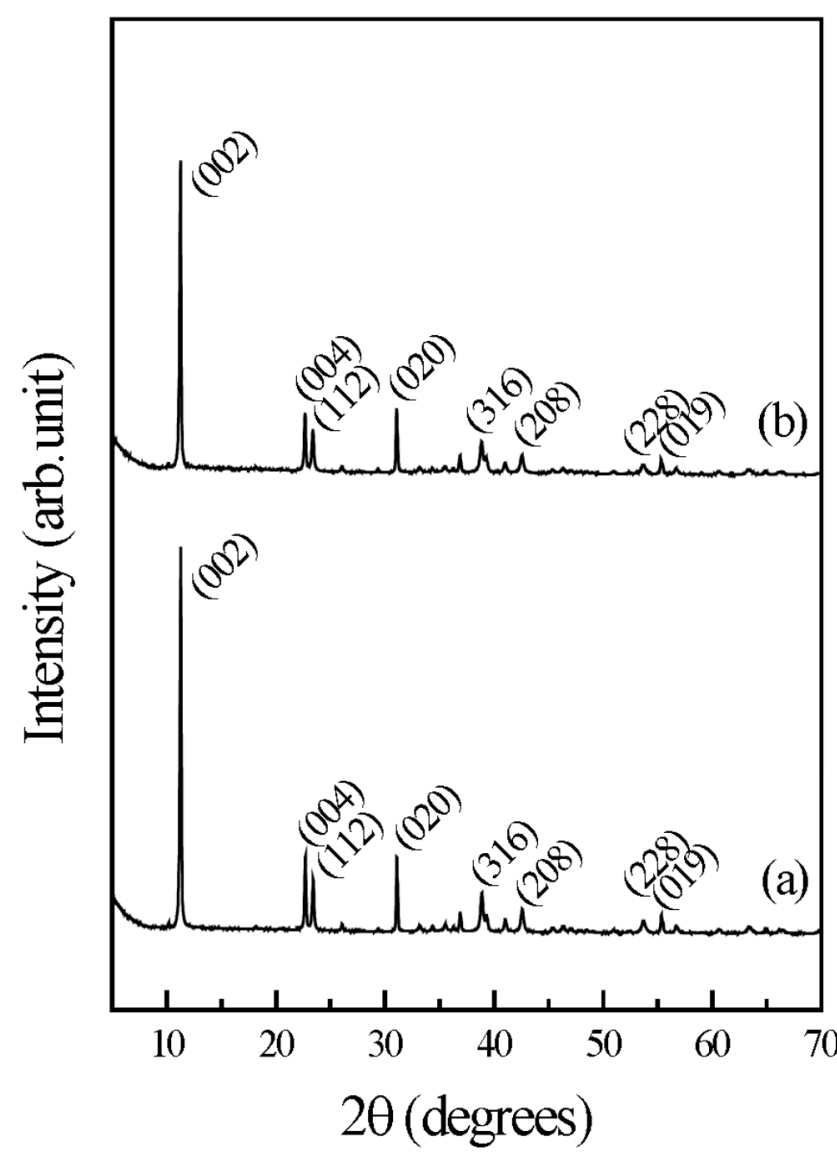

(d)
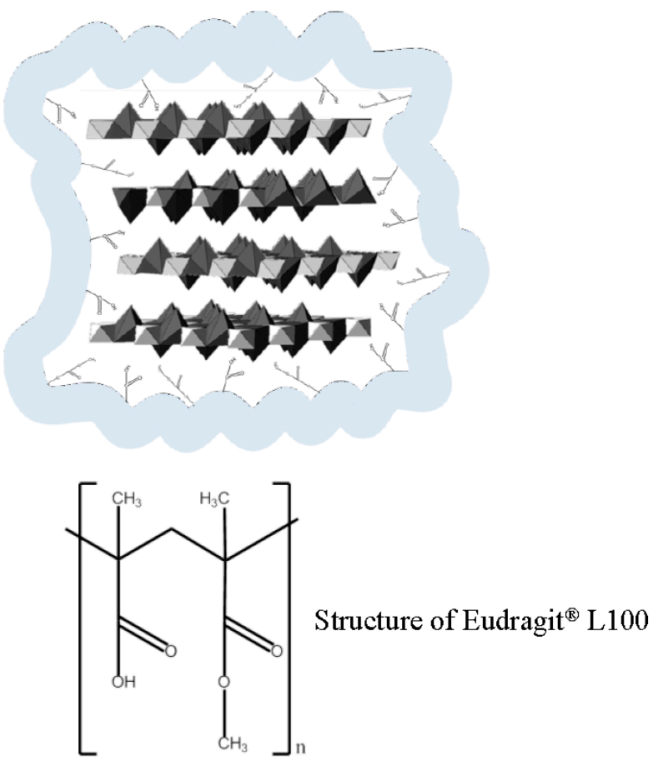

(c)

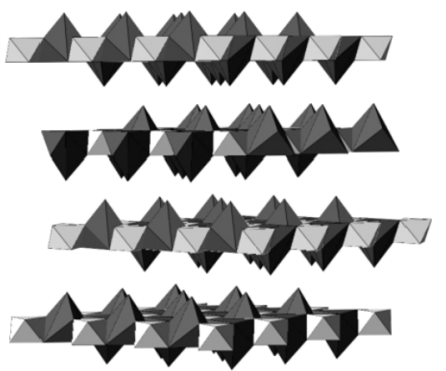

The surface coating of LDH with Eudragit ${ }^{\circledR} \mathrm{L} 100$ was also verified by Fourier transform infrared (FT-IR) spectra (Figure 2). We observed characteristic stretching vibration of Eudragit ${ }^{\circledR} \mathrm{L} 100$ in the spectrum of coated LDHs; peaks at 1482 and $1445 \mathrm{~cm}^{-1}$ were attributed to $\mathrm{CH}_{\mathrm{x}}$ stretching and the peaks at 1252,1195 and $1166 \mathrm{~cm}^{-1}$ are attributed to the ester bond in methacrylate residue. It should be noted that the $\mathrm{COO}^{-}$asymmetric and symmetric stretching vibrations at 1556 and $1392 \mathrm{~cm}^{-1}$ were observed in E-coated CaAl-LDH (Figure 2d), which were not found in the spectrum of Eudragit ${ }^{\circledR}$ L 100 only (Figure 2a). It is suggested that during the coating process, the polymer interacted with the basic surface of LDH, resulting in partial deprotonation, and then the carboxylate residues attached on the positive LDH surface through electrostatic interaction. The percentage of ionic bonding (PIB) was calculated by comparing the vibration energy of $v_{(\mathrm{COOH})}, v_{(\mathrm{COOM})}$, and $v_{(\mathrm{COONa})}(\mathrm{M}$ stands for a counter ion and corresponds to the CaAl-LDH in this study, Equation (2)) [32].

$$
\mathrm{PIB}=\left[v_{(\mathrm{COOH})}-v_{(\mathrm{COOM})}\right] /\left[v_{(\mathrm{COOH})}-v_{(\mathrm{COONa})}\right]
$$

The PIB value for E-coated CaAl-LDH was determined to be 1.06, which means that the bond between Eudragit ${ }^{\circledR}$ L 100 and LDH was strong enough compared with the ionic one. This result suggests that the polymer well covered the surface of LDH nanomaterials through strong electrostatic interaction. 
Figure 2. FT-IR spectra of (a) Eudragit ${ }^{\circledR} \mathrm{L} 100$ (b) $\mathrm{Na}^{+}$-Eudragit ${ }^{\circledR} \mathrm{L} 100$ salt (c) pristine CaAl-LDH and (d) E-coated CaAl-LDH. The dotted lines are positioned and 1727, 1625, $1556,1482,1448,1392,1252,1195$, and $1166 \mathrm{~cm}^{-1}$, respectively.

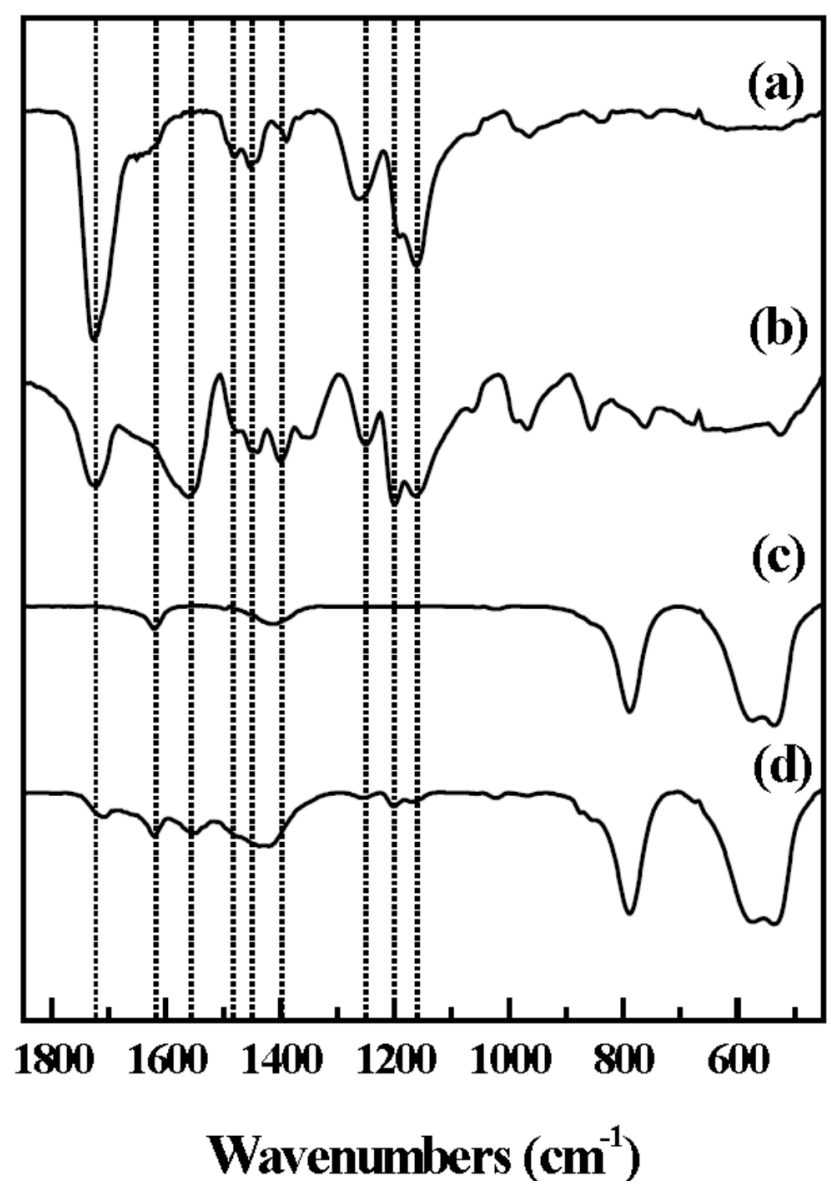

The particle size and morphology of both pristine CaAl-LDH and E-coated CaAl-LDH were examined with scanning electron microscopy (SEM) and transmission electron microscopy (TEM) (Figure 3). The SEM images showed that both CaAl-LDH (before and after coating) had a typical plate-like morphology with particle size distribution ranging from 200 to $500 \mathrm{~nm}$, indicating the average size being preserved throughout the coating process. However, we found a slight morphological change between pristine and coated LDH nanomaterials; the pristine LDH exhibits smooth and flat surface, while the surface of polymer coated LDH became bumpy. The random assembly of polymer chains on the LDH surface was thought to induce a rough surface and blunt edges. According to the TEM analysis, we obtained similar results. TEM images of pristine CaAl-LDH showed primary particle size of approximately $300 \mathrm{~nm}$ with sharp edges (arrow in Figure 3c), whereas, the image for E-coated CaAl-LDH showed dark contrast at center with gray contrast at the edge (dashed arrow in Figure $3 \mathrm{~d}$ ). The blunt morphology with gray contrast in E-coated CaAl-LDH was considered as thin layers of polymer coated on inorganic surface. 
Figure 3. SEM images of (a) pristine CaAl-LDH and (b) E-coated CaAl-LDH. TEM images of (c) pristine CaAl-LDH and (d) E-coated CaAl-LDH. The arrow in (c) and the dashed arrow in (d) stand for the sharp edge of pristine LDH and blunt part of E-coated CaAl-LDH, respectively.
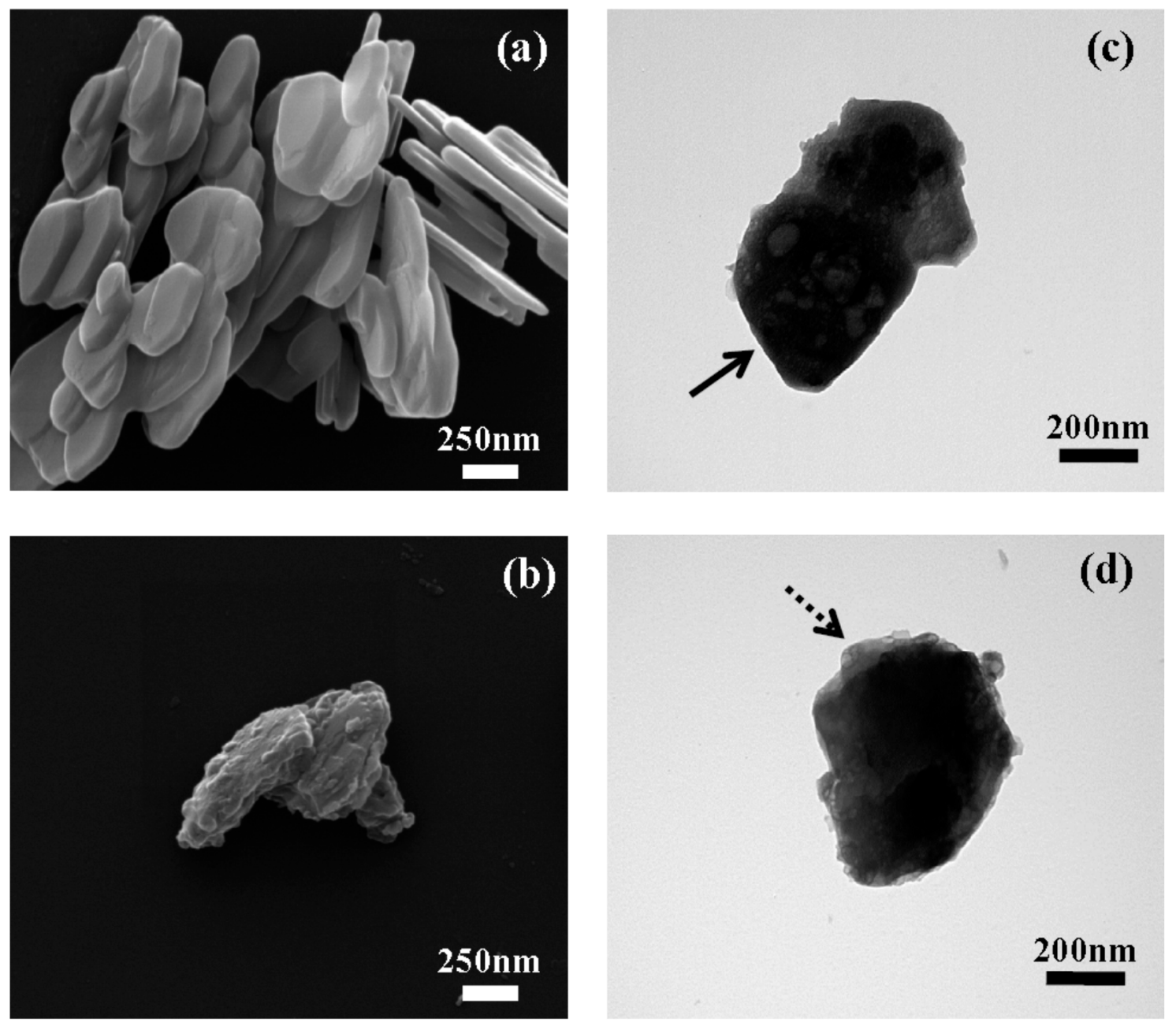

We further evaluated the chemical formula of the prepared samples with inductively coupled plasma-atomic emission spectroscopy (ICP-AES) and thermal analyses. From ICP-AES analysis, the metal ratios of $\mathrm{Ca}: \mathrm{Al}$ for the two samples were determined to be 2.05:1 and 2.07:1, respectively, revealing that there was almost no dissolution of LDH nanomaterials during the polymer coating process. For thermogravimetric (TG) and differential scanning calorimetry (DSC) analysis, the two samples were pre-heated at $100{ }^{\circ} \mathrm{C}$ to remove surface adsorbed water. In the TG curve for pristine LDH (Figure 4a), we observed three steps of weight loss. The first weight loss of $\sim 16.5 \%$ with an endothermic peak at around $300{ }^{\circ} \mathrm{C}$ was attributed to partial dehydroxylation of the LDH layers [33,34]. The second and third weight loss ranging from 490 to $1000{ }^{\circ} \mathrm{C}$ were attributed to be the decomposition of hydroxides and the elimination of interlayer anion. The E-coated CaAl-LDH exhibited similar thermal behavior. The second step ranging from 200 to $485{ }^{\circ} \mathrm{C}$ was due to the partial dehydroxylation of the $\mathrm{LDH}$ layer combined with thermal decomposition of coated Eudragit ${ }^{\circledR}$ L-100. This step showed increased weight loss (23.2\%) compared with the pristine $(18.6 \%)$ and strong exothermic peak at $320^{\circ} \mathrm{C}$, which confirmed that coated polymer combusted during this step. The third and fourth weight losses in the region from 485 to $1000{ }^{\circ} \mathrm{C}$ were attributed to the 
full dehydroxylation and elimination of interlayer anions. Based on the TG result, chemical composition of E-coated CaAl-LDH was determined to be $\left[\mathrm{Ca} 2.07 \mathrm{Al}(\mathrm{OH})_{6.14} \mathrm{Cl}\right]\left[\right.$ Eudragit $^{\circledR}$ L-100] 0.013 , which represents the polymer contents of $0.85 \%(w / w)$ in the coated sample.

Figure 4. TG and DSC curves for (a) pristine CaAl-LDH and (b) E-coated CaAl-LDH. Solid line: TG; dotted line: DSC.

(a)
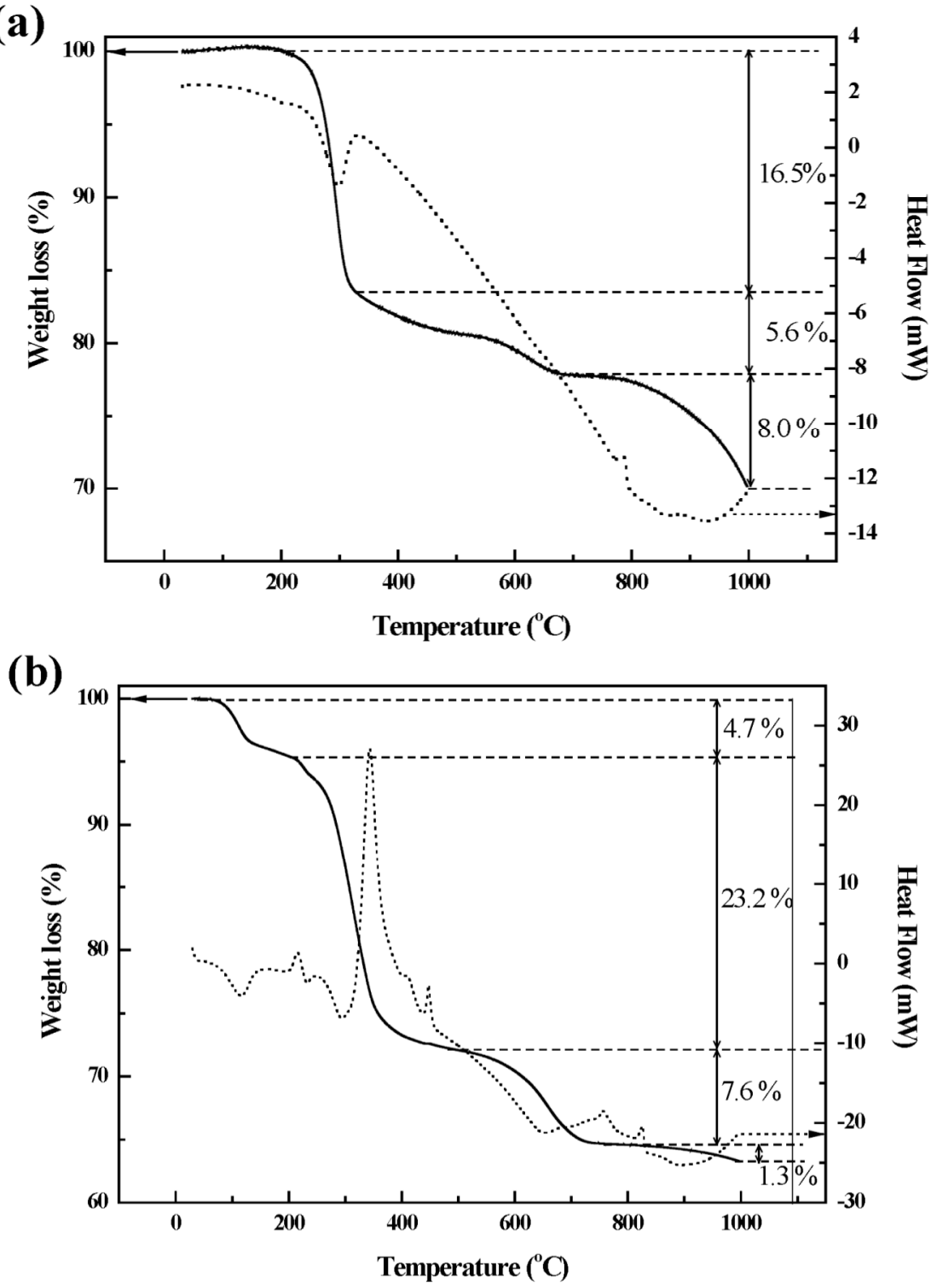

$\mathrm{Ca}^{2+}$ dissolution from LDH lattice with respect to time and $\mathrm{pH}$ conditions was also evaluated. We prepared three different aqueous solutions with $\mathrm{pH}$ values of 1.2, 6.8 and 7.4 in order to simulate gastric, enteric and plasma $\mathrm{pH}$ conditions, respectively. It is generally known that calcium makes hydroxide precipitates at highly basic condition $(\mathrm{pH}>11)$ and their solubility is accelerated with decreasing $\mathrm{pH}$. Thus, it was expected that CaAl-LDH is dissolved into ionic species at all the simulated $\mathrm{pH}$ conditions, with maximum dissolution at $\mathrm{pH} 1.2$ (gastric condition). We measured metal ion concentrations in the supernatant of each suspension and calculated the dissolved weight percentage of metal ions from the LDH lattice. As expected, about $80 \%$ of pristine LDH was dissolved into ionic species at pH 1.2 (Table 1), and less dissolution was found at higher $\mathrm{pH}$ of 6.8 (Table 2) and 7.4 (Table 3), showing approximate 
dissolution of $50 \%$. The $\mathrm{pH}$ dependent dissolution pattern of E-coated CaAl-LDH showed significant difference compared with the pristine LDH. The overall dissolution of polymer coated LDH was suppressed, showing dissolution ratio of $\sim 60 \%, \sim 40 \%$ and $\sim 38 \%$ at $\mathrm{pH} 1.2,6.8$ and 7.4 , respectively. The dissolution of metal ions from E-coated CaAl-LDH was highly suppressed in acidic $\mathrm{pH}$, indicating that the polymer coating effectively protected LDH nanomaterials from acidic condition. Therefore, E-coated CaAl-LDH can be applied as a calcium supplement, targeting calcium absorption in the small intestine ( $\mathrm{pH} \sim 6.8$ ). The solubility of commercially available food grade calcium carbonate obtained from seashell was determined to be approximately $0.7 \mathrm{wt} \%$ in $\mathrm{pH} 1.2$ solution and less than $0.01 \mathrm{wt} \%$ in pH 6.8 and 7.4 solutions. In terms of $\mathrm{Ca}^{2+}$ dissolution under intestinal condition, E-coated CaAl-LDH is expected to have higher bioavailability than commercial calcium carbonates.

Table 1. Time dependent $\mathrm{Ca}^{2+}$ dissolution of CaAl-LDH and E-coated CaAl-LDH at $\mathrm{pH}$ 1.2.

\begin{tabular}{|c|c|c|c|c|c|c|c|c|}
\hline \multirow{3}{*}{$\frac{\text { pH } 1.2}{\text { Material }}$} & \multicolumn{4}{|c|}{ Concentration (ppm) } & \multicolumn{4}{|c|}{ Dissolution Percentage (wt \%) } \\
\hline & \multicolumn{2}{|c|}{ Pristine LDH } & \multicolumn{2}{|c|}{ Coated LDH } & \multicolumn{2}{|c|}{ Pristine LDH } & \multicolumn{2}{|c|}{ Coated LDH } \\
\hline & $\mathrm{Ca}^{2+}$ & $\mathrm{Al}^{3+}$ & $\mathrm{Ca}^{2+}$ & $\mathrm{Al}^{3+}$ & $\mathrm{Ca}^{2+}$ & $\mathrm{Al}^{3+}$ & $\mathrm{Ca}^{2+}$ & $\mathrm{Al}^{3+}$ \\
\hline $30 \mathrm{~min}$ & 10.8 & 3.31 & 6.49 & 2.02 & 82.20 & 76.72 & 52.09 & 49.38 \\
\hline $120 \mathrm{~min}$ & 11.4 & 3.48 & 7.57 & 2.39 & 86.77 & 80.66 & 60.76 & 58.42 \\
\hline $480 \mathrm{~min}$ & 11.0 & 3.53 & 8.57 & 2.77 & 83.72 & 81.82 & 68.79 & 67.71 \\
\hline
\end{tabular}

Table 2. Time dependent $\mathrm{Ca}^{2+}$ dissolution of CaAl-LDH and E-coated CaAl-LDH at $\mathrm{pH} 6.8$.

\begin{tabular}{|c|c|c|c|c|c|c|c|c|}
\hline \multirow{3}{*}{$\begin{array}{c}\text { pH } 6.8 \\
\text { Material } \\
\text { Metal Time }\end{array}$} & \multicolumn{4}{|c|}{ Concentration (ppm) } & \multicolumn{4}{|c|}{ Dissolution Percentage (wt \%) } \\
\hline & \multicolumn{2}{|c|}{ Pristine LDH } & \multicolumn{2}{|c|}{ Coated LDH } & \multicolumn{2}{|c|}{ Pristine LDH } & \multicolumn{2}{|c|}{ Coated LDH } \\
\hline & & & & & & & & \\
\hline & & & & & & & & \\
\hline & & & & & & & & \\
\hline $480 \mathrm{~min}$ & 6.37 & 2.49 & 5.03 & 1.78 & 48.48 & 57.71 & 40.38 & 43.51 \\
\hline
\end{tabular}

Table 3. Time dependent $\mathrm{Ca}^{2+}$ dissolution of CaAl-LDH and E-coated CaAl-LDH at $\mathrm{pH}$ 7.4.

\begin{tabular}{|c|c|c|c|c|c|c|c|c|}
\hline \multirow{3}{*}{$\begin{array}{c}\text { pH } 7.4 \\
\text { Material } \\
\text { Metal Time }\end{array}$} & \multicolumn{4}{|c|}{ Concentration (ppm) } & \multicolumn{4}{|c|}{ Dissolution Percentage (wt \%) } \\
\hline & \multicolumn{2}{|c|}{ Pristine LDH } & \multicolumn{2}{|c|}{ Coated LDH } & \multicolumn{2}{|c|}{ Pristine LDH } & \multicolumn{2}{|c|}{ Coated LDH } \\
\hline & & & & & & & & \\
\hline & & & & & & & & \\
\hline & & & & & 46. & & & 39.35 \\
\hline $480 \mathrm{~min}$ & 6.45 & 2.64 & 5.05 & 2.18 & 49.09 & 61.19 & 40.54 & 53.29 \\
\hline
\end{tabular}

To be applied as a food supplement, biocompatibility of nanomaterials is also an important factor. Hence, cytotoxicity of CaAl-LDH and E-coated CaAl-LDH was evaluated in human epithelial colorectal CaCo-2 cells. As shown in Figure 5, both nanoparticles did not exhibit cytotoxic effect up to the highest concentration tested, $1000 \mu \mathrm{g} / \mathrm{mL}$, after $72 \mathrm{~h}$ incubation. The low cytotoxicity of CaAl-LDH is in good agreement with our previous reports [35,36], showing little effect of LDHs on cell proliferation and viability of cells. 
Figure 5. Cell viability of CaAl-LDH treated CaCo-2 cells after $72 \mathrm{~h}$ incubation, measured by water-soluble tetrazolium (WST)-1 assay.

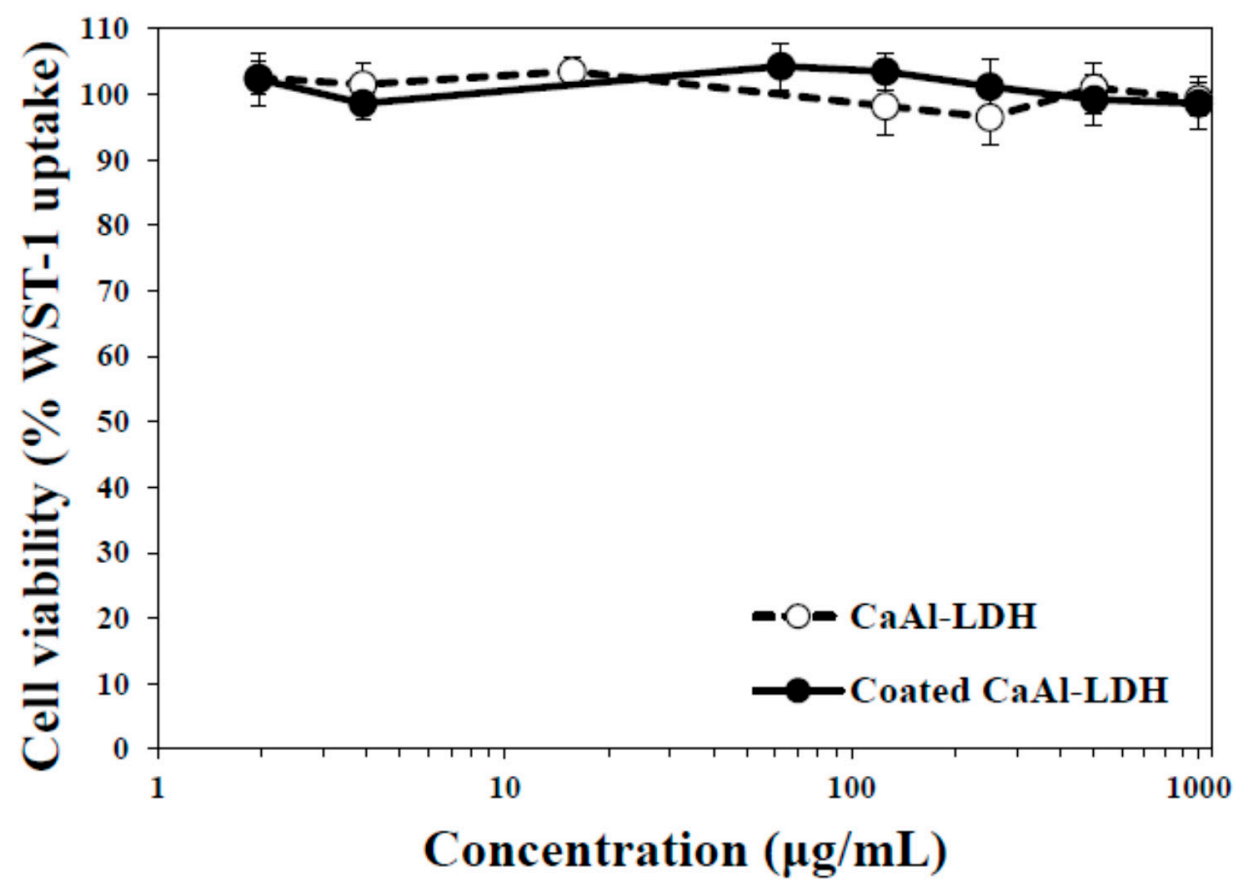

Intracellular $\mathrm{Ca}^{2+}$ amount in CaAl-LDH exposed cells was traced with a cell permeant fluorescent probe, Calcium Green ${ }^{\mathrm{TM}_{-}}$, which increases green fluorescence upon binding $\mathrm{Ca}^{2+}$. Figure 6 showed that calcium concentration increased in CaAl-LDH treated cells as incubation time increased. Interestingly, intracellular calcium level dramatically increased in calcium containing buffer, as compared with that in calcium free buffer. This result implies that nanomaterials interact strongly with $\mathrm{Ca}^{2+}$, probably forming $\mathrm{Ca}^{2+}-\mathrm{CaAl}-\mathrm{LDH}$ complex, which facilitates free $\mathrm{Ca}^{2+}$ uptake into cells. On the other hand, increased calcium level in calcium free buffer directly indicates intracellular uptake amount of CaAl-LDH into cells. This might be closely associated with the fact that LDH nanoparticles can be internalized into cells via the endocytosis pathway, as particulate forms [37]. Significantly increased calcium levels was not found in cells incubated with commercially available food grade calcium carbonate (data not shown), probably related to its bulk size.

Pharmacokinetics of nanoparticles was evaluated after a single dose oral administration to rats, in comparison with $\mathrm{CaCl}_{2}$ as a calcium ion reference (Figure 7). Plasma concentration-time curve of E-coated CaAl-LDH demonstrated that calcium concentration rapidly increased, showing peak concentration at $0.5 \mathrm{~h}$, and decreased within $1 \mathrm{~h}$. On the other hand, calcium ions were determined to be more rapidly and highly absorbed into the blood stream. When pharmacokinetic parameters between E-coated CaAl-LDH and calcium ion were compared (Table 4), high $\mathrm{C}_{\max }$ and AUC values for calcium ions were found, indicating high absorption amount. However, when absorption efficiency (\%) was considered, calculated by total plasma calcium concentration divided by administered amount, high oral absorption efficiency (about 8\%) was found for E-coated CaAl-LDH. This is because calcium content in $\mathrm{LDH}$ nanomaterials is much lower than that in $\mathrm{CaCl}_{2}$, suggesting that E-coated CaAl-LDH was effective to enhance oral calcium absorption. It is worthy to note that oral absorption efficiency of 
commercially available food grade calcium carbonate was about $4 \%$ (data not shown), which is highly consistent with its known oral absorption [18].

Figure 6. Intracellular calcium levels in $\mathrm{CaCo}-2$ cells exposed to $\mathrm{CaAl}-\mathrm{LDH}$ nanomaterials, measured by Calcium Green ${ }^{\mathrm{TM}}-1$.

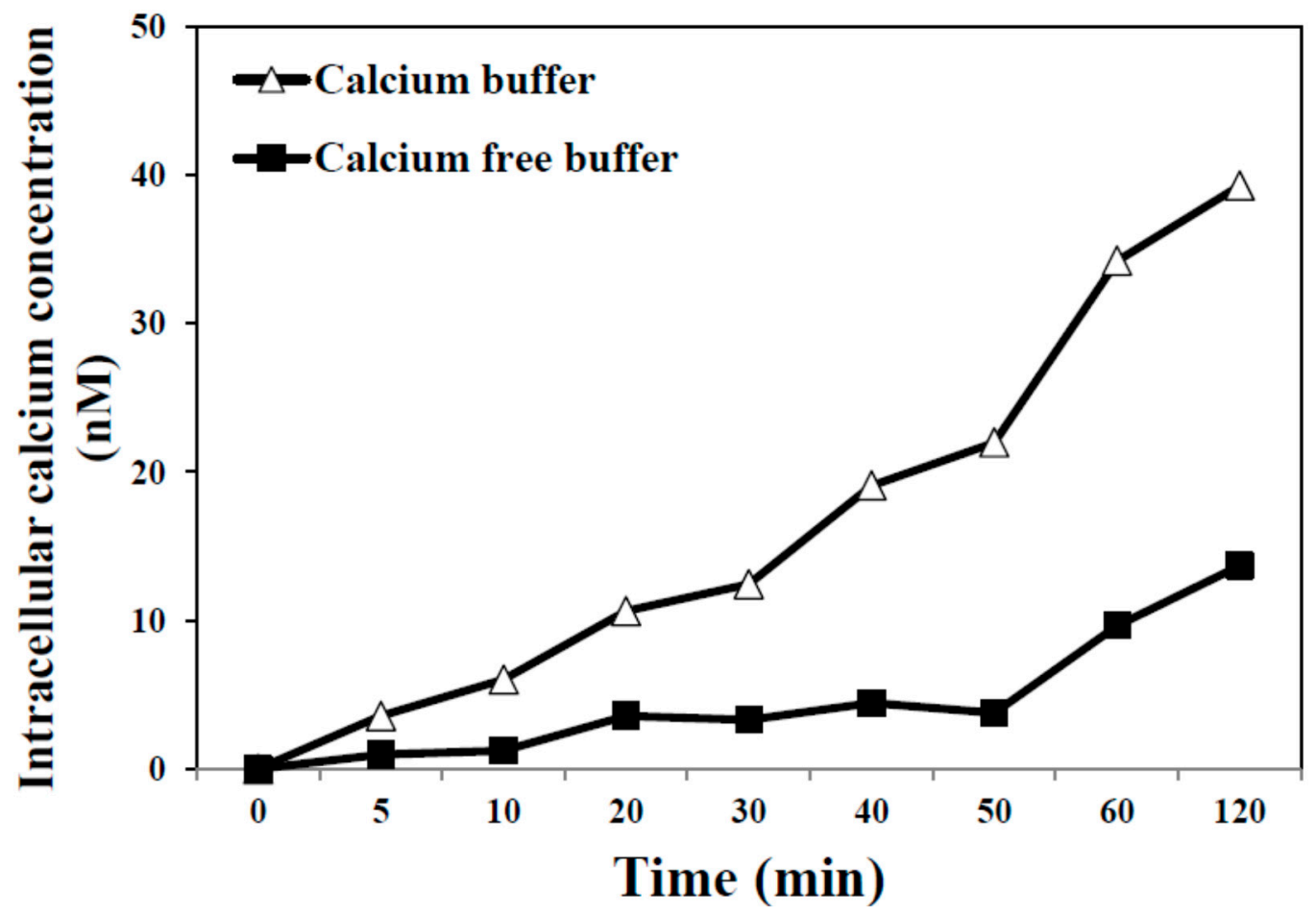

Figure 7. Plasma concentration-time curve of E-coated CaAl-LDH after a single dose oral administration to rats. Equivalent amount of $\mathrm{CaCl}_{2}$ based on calcium content was also treated as a control group.

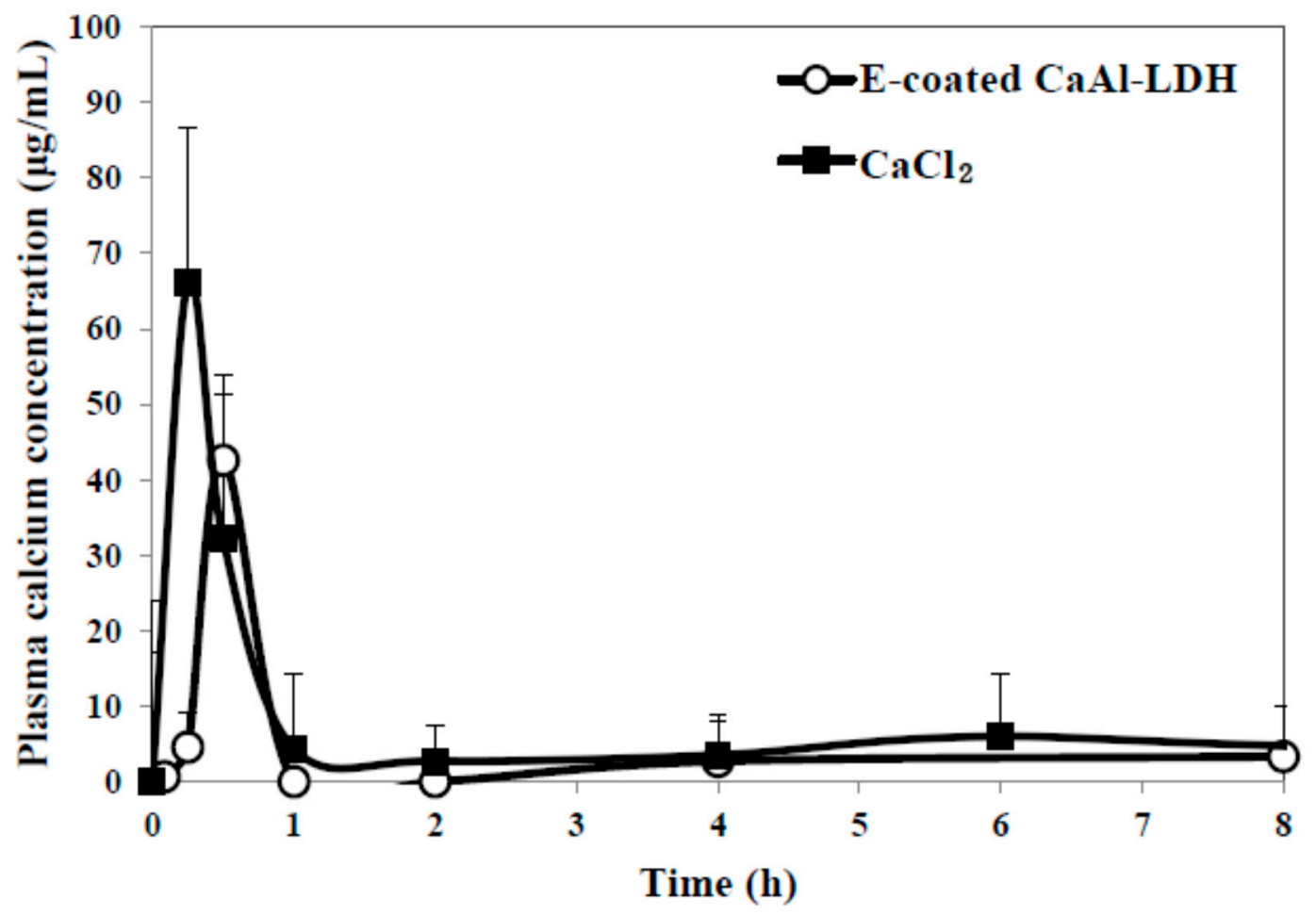


Table 4. Pharmacokinetic parameters of E-coated CaAl-LDH, as compared with $\mathrm{CaCl}_{2}$ after a single dose oral administration to rats.

\begin{tabular}{ccc}
\hline Pharmacokinetic Parameters & E-Coated CaAl-LDH & CaCl $_{\mathbf{2}}$ \\
\hline $\mathrm{C}_{\max }(\mu \mathrm{g} / \mathrm{mL})$ & $42.55 \pm 6.14^{\mathrm{a}}$ & $66.16 \pm 12.98^{\mathrm{b}}$ \\
$\mathrm{T}_{\max }(\mathrm{h})$ & 0.5 & 0.25 \\
$\mathrm{AUC}(\mathrm{h} \times \mu \mathrm{g} / \mathrm{mL})$ & $31.56 \pm 0.62^{\mathrm{a}}$ & $39.19 \pm 5.74^{\mathrm{b}}$ \\
$\mathrm{T}_{1 / 2}(\mathrm{~h})$ & $0.65 \pm 0.05^{\mathrm{a}}$ & $0.77 \pm 0.04^{\mathrm{b}}$ \\
$\mathrm{MRT}(\mathrm{h})$ & $1.24 \pm 0.06^{\mathrm{b}}$ & $0.97 \pm 0.09^{\mathrm{a}}$ \\
Absorption $(\%) *$ & $8.13 \pm 0.16^{\mathrm{b}}$ & $3.05 \pm 0.45^{\mathrm{a}}$ \\
\hline
\end{tabular}

a,b Significant difference between E-coated CaAl-LDH and $\mathrm{CaCl}_{2} ; *$ Absorption was calculated based on AUC values.

Finally, acute toxicity of E-coated CaAl-LDH was evaluated after a single dose oral administration to mice. No mortality, significant decrease in body weight and abnormal behaviors or symptoms were observed up to the dose of $2000 \mathrm{mg} / \mathrm{kg}$ (Figure 8). This result clearly demonstrated low acute toxicity of the present nanoparticles, suggesting their promising potential as a calcium supplement. All the results suggest that E-coated CaAl-LDH can be effective to enhance oral absorption and bioavailability of calcium at the systemic level.

Figure 8. Change in body weight in mice after a single dose oral administration of E-coated CaAl-LDH.

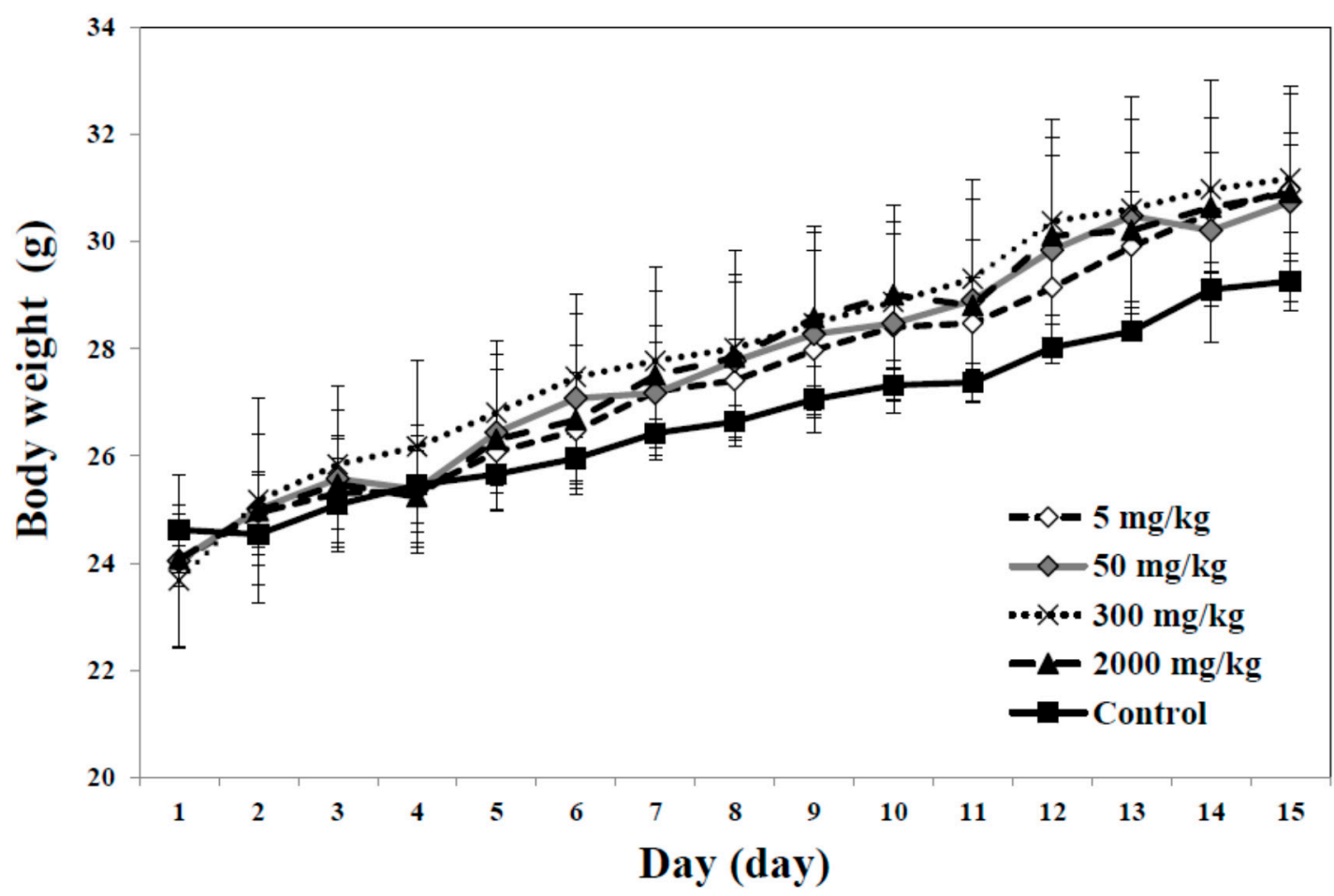




\section{Experimental Section}

\subsection{Preparation of Ca-Containing $L D H$}

$\mathrm{CaCl}_{2} \cdot 2 \mathrm{H}_{2} \mathrm{O}$ and $\mathrm{NaOH}$ were obtained from Daejung Chemicals and Metals Co., Ltd. (Siheung-si, Gyonggi-do, Korea), $\mathrm{AlCl}_{3} \cdot 6 \mathrm{H}_{2} \mathrm{O}$ was purchased from Sigma Aldrich Co., Ltd. (St. Louis, MO, USA) and Eudragit ${ }^{\circledR}$ L 100 was purchased from Evonik Industries (Essen, North Rhine-Westphalia, Germany). Ethyl alcohol (95\%) was obtained from SK Chemicals (Seongnam-si, Gyonggi-do, Korea). All the reagents were used without further purification. Food grade calcium carbonates, produced by seashells, were purchased from Apexel. Co., Ltd. (Pohang-si, Gyeongsangbuk-do, Korea).

LDH consisted of calcium and aluminum (CaAl-LDH) was prepared through coprecipitation method, as previously reported [38]. Typically, $\mathrm{NaOH}$ solution $(1.26 \mathrm{M})$ was added dropwise to the mixed metal chloride solution $\left(0.315 \mathrm{M}\right.$ and $0.1575 \mathrm{M}$ for $\mathrm{CaCl}_{2} \cdot 2 \mathrm{H}_{2} \mathrm{O}$ and $\mathrm{AlCl}_{3} \cdot 6 \mathrm{H}_{2} \mathrm{O}$, respectively) until the $\mathrm{pH}$ reached to around 11.5. The obtained white suspension was aged for $24 \mathrm{~h}$ at room temperature with vigorous stirring. Then, the resulting precipitates were filtered and washed thoroughly with deionized water and dried in a vacuum at $40^{\circ} \mathrm{C}$.

\subsection{Coating of Nanoparticles with an Enteric Polymer}

In order to coat the surface of LDH with Eudragit ${ }^{\circledR}$ L100 (E-coated CaAl-LDH), the polymer $(0.247 \mathrm{~g})$ was dissolved in ethanol $(250 \mathrm{~mL})$. Then, $1 \mathrm{~g}$ of CaAl-LDH was dispersed into $250 \mathrm{~mL}$ ethanol and Eudragit ${ }^{\circledR} \mathrm{L} 100$ solution was added dropwise. After stirring the suspension for $6 \mathrm{~h}$, the precipitate was obtained by filtration and dried in a vacuum at $40{ }^{\circ} \mathrm{C}$.

\subsection{Physicochemical Characterization}

Powder XRD of pristine CaAl-LDH and E-coated CaAl-LDH were obtained with Bruker AXS D2 phaser with increments of degree and time step of $0.02^{\circ}$ and $1 \mathrm{sec} / \mathrm{step}$, respectively. FT-IR (Spectrum one B.v5.0, Perkin Elmer, Waltham, MA, USA) spectroscopy was performed with conventional $\mathrm{KBr}$ methods. The chemical composition and thermal behavior of all prepared samples were obtained with ICP-AES (Optima-4300 DV, Perkin Elmer, Waltham, MA, USA), TG (SDT-Q600, TA Instruments, New Castle, PA, USA) and DSC (SDT-Q600, TA Instruments, New Castle, PA, USA). The particle size and morphology of prepared samples were observed with TEM (JEM1010 at National instrumentation center for environmental management in Seoul National University, Korea) and SEM (Quanta 250 FEG at Yonsei University in Wonju, Korea).

\subsection{Dissolution Test}

Dissolution of $\mathrm{Ca}^{2+}$ from either pristine CaAl-LDH or E-coated CaAl-LDH was evaluated in three different aqueous solutions with $\mathrm{pH}$ at 1.2, 6.8, and 7.4, simulating gastric, enteric and plasma $\mathrm{pH}$ conditions, respectively. To evaluate the $\mathrm{pH}$ dependent dissolution of nanomaterials, only $\mathrm{pH}$ was controlled without addition of enzyme or salt. Either CaAl-LDH or E-coated CaAl-LDH (200 mg, respectively) was dispersed in each simulated solution. At time points of $0.5,2$ and $8 \mathrm{~h}, 2 \mathrm{~mL}$ of solution 
was collected and the supernatant was massed up to $50 \mathrm{~mL}$ for ICP-AES analysis (Optima-4300 DV, Perkin Elmer, Waltham, MA, USA).

\subsection{Cell Viability}

Human epithelial colorectal adenocarcinoma CaCo-2 cells were purchased from the Korean Cell Line Bank and cultured in Minimum Essential Media (MEM, Welgene, Ltd., Daegu, Korea), under a humidified atmosphere $\left(5 \% \mathrm{CO}_{2}\right.$ plus $95 \%$ air $)$ at $37{ }^{\circ} \mathrm{C}$. The medium was supplemented with $10 \%$ heat inactivated fetal bovine serum (Welgene Ltd., Daegu, Korea), 100 units $/ \mathrm{mL}$ penicillin and $100 \mu \mathrm{g} / \mathrm{mL}$ streptomycin. Cells $\left(5 \times 10^{3}\right.$ cells $\left./ 100 \mu \mathrm{L}\right)$ were seeded onto 96 -well plates and incubated overnight at $37{ }^{\circ} \mathrm{C}$ in $5 \% \mathrm{CO}_{2}$ atmosphere. The medium in the wells was then replaced with fresh medium containing nanoparticles $(1-1000 \mu \mathrm{g} / \mathrm{mL})$ and incubation continued for $72 \mathrm{~h}$. The effect of the nanoparticles on cell proliferation was determined by WST-1 assay (Roche Ltd., Basel, Switzerland). Briefly, $10 \mu \mathrm{L}$ of WST-1 solution (Roche) was added to each well and the plates were further incubated. After $4 \mathrm{~h}$, the absorbance was measured with a plate reader at $440 \mathrm{~nm}$. Cells incubated without nanomaterials were used as a control.

\subsection{Intracellular Uptake}

Intracellular uptake of $\mathrm{Ca}^{2+}$ from nanomaterials was measured with Calcium Green ${ }^{\mathrm{TM}}-1$ (Molecular Probes, Eugene, OR, USA). Cells were grown at $5 \times 10^{4}$ cells/96 well and then incubated with CaAl-LDH nanoparticles at $250 \mu \mathrm{g} / \mathrm{mL}$ in the presence of $2 \mu \mathrm{M}$ Calcium Green ${ }^{\mathrm{TM}_{-}} 1$ in Krebs-Ringer-HEPES solution (KRH, American Research Products, Inc., Waltham, MA, USA) containing (mM/L) $\mathrm{NaCl}$ 125.0, $\mathrm{KCl} 5.0, \mathrm{KH}_{2} \mathrm{PO}_{4}$ 1.2, $\mathrm{CaCl}_{2} 2.0, \mathrm{MgSO}_{4}$ 1.2, glucose 6.0 and HEPES 25.0, and adjusted to $\mathrm{pH}$ 7.4. For experiments requiring calcium-free solution, $\mathrm{CaCl}_{2}$ was omitted from $\mathrm{KRH}$ solution and $1 \mathrm{mM}$ EDTA was added to complex any trace of $\mathrm{Ca}^{2+}$ contaminant. Fluorescence intensity of the $\mathrm{Ca}^{2+}$-bound indicator was measured with a fluorescence microplate reader (Dynex Technology Inc., Chantilly, VA, USA), with excitation at $506 \mathrm{~nm}$ and emission at $531 \mathrm{~nm}$. The amount of intracellular $\mathrm{Ca}^{2+}$ was calculated by performing a calibration with external standards of calcium and Green ${ }^{\mathrm{TM}}-1$, according to the manufacturer's protocol.

\subsection{Pharmacokinetics}

Male SD rats, aged 5 weeks and weighing 180-200 g, were purchased from the G-Bio (Gyeonggi-Do, Korea). The animals were housed in plastic lab animal cages in a ventilated room. The room was maintained at $20 \pm 2{ }^{\circ} \mathrm{C}$ and $60 \% \pm 10 \%$ relative humidity with a $12 \mathrm{~h}$ light/dark cycle. Water and commercial laboratory complete food for mice were available ad libitum. They were acclimated to this environment for 7 days before treatment. All animal experiments were performed in compliance with the Animal and Ethics Review Committee of the Seoul Women's University.

The plasma concentration of calcium was analyzed after oral administration of E-coated CaAl-LDH or calcium chloride $\left(\mathrm{CaCl}_{2}\right)$ as a control to each group of six male rats. Four mg of calcium based on calcium content in E-coated CaAl-LDH or $\mathrm{CaCl}_{2}$ were administered via oral gavage. The blood samples (about $0.2 \mathrm{~mL}$ ) were collected via tail vein at several time points $(0,15$ and $30 \mathrm{~min}, 1,2,4,6$, and $8 \mathrm{~h}$ ). 
The blood sample at $0 \mathrm{~h}$ before oral administration was used to determine the basal calcium level in the plasma. The blood samples were centrifuged at $3000 \mathrm{rpm}$ for $15 \mathrm{~min}$ at $4{ }^{\circ} \mathrm{C}$ to obtain the plasma and stored at $-70{ }^{\circ} \mathrm{C}$ before analysis.

The plasma was digested in $3 \mathrm{~mL}$ of ultrapure nitric acid overnight, heated at about $160{ }^{\circ} \mathrm{C}$, and then, $0.5 \mathrm{~mL}$ of $\mathrm{H}_{2} \mathrm{O}_{2}$ was added. Each sample mixture was heated until completely digested. The remaining solution was then removed by heating until the solutions were colorless and clear. The solution were finally diluted to $5 \mathrm{~mL}$ with ultrapure water and filtered with a $0.45 \mu \mathrm{m}$ pore filter. The total calcium content was determined using ICP-AES (Jobin Yvon Horiba, JY2000 Ultrace, Longjumeau, France). The following pharmacokinetic parameters were estimated using Kinetica version 4.4 (Thermo Electron Corporation, Waltham, MA, USA): maximum concentration $\left(\mathrm{C}_{\max }\right)$, time to maximum concentration $\left(\mathrm{T}_{\max }\right)$, area under the plasma concentration-time curve (AUC), half-life $\left(\mathrm{T}_{1 / 2}\right)$ and mean residence time (MRT).

\subsection{Acute Toxicity}

Male Balb/c mice, aged 6 weeks and weighing 20-22 g, were purchased from the G-Bio (Gyeonggi-do, Korea). The experiments to determine the LD 50 (lethal dose 50\%) of LDH were designed in accordance with the method provided by the OECD (OECD guideline 423). Prior to dosing, food but not water was withheld for $4 \mathrm{~h}$. E-coated CaAl-LDH was homogeneously suspended in $0.9 \%$ saline by vortexing and ultrasonicating the suspension for 5 min at $42 \mathrm{kHz}$ (Vibra Cell Sonics \& Materials Inc., Newtown, CT, USA). And, four different concentrations of samples (5, 50, 300 and $2000 \mathrm{mg} / \mathrm{kg}$ ) were administered to each group of three mice via oral gavage. A group of three mice, receiving identical volumes of $0.9 \%$ saline, served as a control. Survival rate, body weight change, behaviors and symptoms of mice were carefully recorded daily after treatment.

\subsection{Statistical Analysis}

The data are presented as means \pm standard deviations. For statistical analysis, experimental values were compared between experimental groups. One-way analysis of variance (ANOVA) in SAS software (Tukey's Test, Version 11.0, SAS Institute Inc., Cary, NC, USA) was used to determine the significances of difference between groups. Statistical significance was accepted for $p$ values of less than 0.05.

\section{Conclusions}

We demonstrated the potential of polymer-coated CaAl-LDH as a calcium supplement. The pristine CaAl-LDH was well prepared through a simple coprecipitation route, and the coating of CaAl-LDH with enteric polymer Eudragit ${ }^{\circledR}$ L 100 (E-coated CaAl-LDH) was carried out in ethanol condition to avoid unintended intercalation of polymer into the LDH interlayer. Physicochemical characterizations revealed that the pristine LDH with hydrocalumite structure was well synthesized and the polymer was effectively coated on the LDH surface with minimal content. Moreover, the dissolution of calcium ions from E-coated CaAl-LDH at pH 1.2 was strongly suppressed compared with the uncoated one. Both pristine CaAl-LDH and E-coated CaAl-LDH did not cause cytotoxic effects on human epithelial colorectal cells, while a remarkably increased calcium level was detected in the nanomaterial-treated cells. Pharmacokinetic analysis clearly demonstrated oral absorption efficiency of E-coated CaAl-LDH, without 
causing any acute toxicity in vivo. It was therefore concluded that CaAl-LDHs with an appropriate coating has great potential as a calcium supplement.

\section{Acknowledgments}

This work was financially supported by a grant from the Postharvest Research Project (PJ01050201) of RDA, Republic of Korea and by the Ministry of Science, ICT and Future Planning (MSIP) of the Korean government, and by the Basic Science Research Program through the National Research Foundation of Korea (NRF) funded by the Ministry of Education, Science and Technology (2013R1A1A3009283).

\section{Author Contributions}

Soo-Jin Choi and Jae-Min Oh designed the experiments and draft the manuscript. Tae-Hyun Kim synthesized Ca-Al LDH and carried out all physicochemical analysis. Jeong-A Lee performed cell culture, animal experiments and statistical analysis. All authors read and approved the final manuscript.

\section{Conflicts of Interest}

The authors declare no conflict of interest.

\section{References}

1. Oh, J.M.; Kwak, S.Y.; Choy, J.H. Intracrystalline structure of DNA molecules stabilized in the layered double hydroxide. J. Phys. Chem. Solids 2006, 67, 1028-1031.

2. Colvin, V.L. The potential environmental impact of engineered nanomaterials. Nat. Biotechnol. 2003, 21, 1166-1170.

3. Kang, J.H.; Paek, S.M.; Hwang, S.J.; Choy, J.H. Pre-swelled nanostructured electrode for lithium ion battery: $\mathrm{TiO}_{2}$-pillared layered $\mathrm{MnO}_{2}$. J. Mater. Chem. 2010, 20, 2033-2038.

4. Burgi, B.R.; Pradeep, T. Societal implications of nanoscience and nanotechnology in developing countries. Curr. Sci. India 2006, 90, 645-658.

5. Oh, J.M.; Park, D.H.; Choi, S.J.; Choy, J.H. LDH Nanocontainers as bio-reservoirs and drug delivery carriers. Recent Pat. Nanotechnol. 2012, 6, 200-217.

6. Biswick, T.; Park, D.H.; Shul, Y.G.; Hwang, S.J.; Choy, J.H. UV Screening of ferulic acid-zinc basic salt nanohybrid with controlled release rate. J. Nanosci. Nanotechnol. 2011, 11, 413-416.

7. Oh, J.M.; Biswick, T.T.; Choy, J.H. Layered nanomaterials for green materials. J. Mater. Chem. 2009, 19, 2553-2563.

8. Park, J.K.; Bin Choy, Y.; Oh, J.M.; Kim, J.Y.; Hwang, S.J.; Choy, J.H. Controlled release of donepezil intercalated in smectite clays. Int. J. Pharm. 2008, 359, 198-204.

9. Hong, M.M.; Oh, J.M.; Choy, J.H. Encapsulation of flavor molecules, 4-hydroxy-3-methoxy benzoic acid, into layered inorganic nanoparticles for controlled release of Flavor. J. Nanosci. Nanotechnol. 2008, 8, 5018-5021.

10. Choi, S.J.; Oh, J.M.; Choy, J.H. Human-related application and nanotoxicology of inorganic particles: Complementary aspects. J. Mater. Chem. 2008, 18, 615-620. 
11. Gunjakar, J.L.; Kim, T.W.; Kim, H.N.; Kim, I.Y.; Hwang, S.J. Mesoporous layer-by-layer ordered nanohybrids of layered double hydroxide and layered metal oxide: Highly active visible light photocatalysts with improved chemical stability. J. Am. Chem. Soc. 2011, 133, 14998-15007.

12. Baek, M.; Choy, J.H.; Choi, S.J. Montmorillonite intercalated with glutathione for antioxidant delivery: Synthesis, characterization, and bioavailability evaluation. Int. J. Pharm. 2012, 425, 29-34.

13. Lippard, S.J.; B., J.M. Choice, uptake, and assembly of metal-containing units in biology. In Princlples of Bioinorganic Chemistry, 1st ed.; University Science Book: Mill Valley, CA, USA, 1994; pp.103-137.

14. Bootman, M.D.; Berridge, M.J. The elemental principles of calcium signaling. Cell 1995, 83, 675-678.

15. Ghosh, A.; Greenberg, M.E. Calcium signaling in neurons: Molecular mechanisms and cellular consequences. Science 1995, 268, 239-247.

16. Straub, D.A. Calcium supplementation in clinical practice: A review of forms, doses, and indications. Nutr. Clin. Pract. 2007, 22, 286-296.

17. PJ, G. Calcium Salt, 1st ed.; Prescriber's Letter: Stockton, CA, USA, 2000; Document 1603013.

18. Hanzlik, R.P.; Fowler, S.C.; Fisher, D.H. Relative bioavailability of calcium from calcium formate, calcium citrate, and calcium carbonate. J. Pharmacol. Exp. Ther. 2005, 313, 1217-1222.

19. Choy, J.H.; Jung, J.S.; Oh, J.M.; Park, M.; Jeong, J.; Kang, Y.K.; Han, O.J. Layered double hydroxide as an efficient drug reservoir for folate derivatives. Biomaterterials 2004, 25, 3059-3064.

20. Oh, J.M.; Park, M.; Kim, S.-T.; Jung, J.Y.; Kang, Y.G.; Choy, J.H. Efficient delivery of anticancer drug MTX through MTX-LDH nanohybrid system. J. Phys. Chem. Solids 2006, 67, 1024-1027.

21. Choy, J.H.; Kwak, S.Y.; Park, J.S.; Jeong, Y.J. Cellular uptake behavior of $\left[\gamma^{32 \mathrm{P}}\right]$ labeled ATP-LDH nanohybrids. J. Mater. Chem. 2001, 11, 1671-1674.

22. Oh, J.M.; Choi, S.J.; Kim, S.T.; Choy, J.H. Cellular uptake mechanism of an inorganic nanovehicle and its drug conjugates: Enhanced efficacy due to clathrin-mediated endocytosis. Bioconjug. Chem. 2006, 17, 1411-1417.

23. Li, B.; He, J.; Evans, D.G.; Duan, X. Enteric-coated layered double hydroxides as a controlled release drug delivery system. Int. J. Pharm. 2004, 287, 89-95.

24. Helbock, H.J.; Forte, J.G.; Saltman, P. The mechanism of calcium transport by rat intestine. BBA Biophys. Photosyn. 1966, 126, 81-93.

25. Hejazi, R.; Amiji, M. Chitosan-based delivery systems: Physicochemical properties and pharmaceutical applications. In Polymeric Biomaterials, 2nd ed.; Severian Dumitriu; Marcel Dekker: New York, NY, USA, 2002; pp. 213-237

26. Rousselot, I.; Taviot-Guého, C.; Leroux, F.; Léone, P.; Palvadeau, P.; Besse, J.P. Insights on the structural chemistry of hydrocalumite and hydrotalcite-like materials: Investigation of the series $\mathrm{Ca}_{2} \mathrm{M}^{3+}(\mathrm{OH})_{6} \mathrm{Cl} \cdot 2 \mathrm{H}_{2} \mathrm{O}\left(\mathrm{M}^{3+}: \mathrm{Al}^{3+}, \mathrm{Ga}^{3+}, \mathrm{Fe}^{3+}\right.$, and $\left.\mathrm{Sc}^{3+}\right)$ by X-Ray powder diffraction. J. Solid State Chem. 2002, 167, 137-144.

27. Cullity, B. Elements of X-ray Dffiaction, 2nd ed.; Addison-Wesley Publishing Company Inc.: Boston, MA, USA, 1978; pp. 82-87.

28. Leroux, F.; Aranda, P.; Besse, J.-P.; Ruiz-Hitzky, E. Intercalation of poly(ethylene oxide) derivatives into layered double hydroxides. Eur. J. Inorg. Chem. 2003, 2003, 1242-1251. 
29. Nakayama, H.; Wada, N.; Tsuhako, M. Intercalation of amino acids and peptides into Mg-Al layered double hydroxide by reconstruction method. Int. J. Pharm. 2004, 269, 469-478.

30. Plank, J.; Dai, Z.; Andres, P.R. Preparation and characterization of new Ca-Al-polycarboxylate layered double hydroxides. Mater. Lett. 2006, 60, 3614-3617.

31. Sohmiya, M.; Omata, S.; Ogawa, M. Two dimensional size controlled confinement of poly(vinyl pyrrolidone) in the interlayer space of swelling clay mineral. Polym. Chem. 2012, 3 , 1069-1074.

32. Chen, J.P.; Hong, L.; Wu, S.; Wang, L. Elucidation of interactions between metal ions and Ca alginate-based ion-exchange resin by spectroscopic analysis and modeling simulation. Langmuir 2002, 18, 9413-9421.

33. Rives, V.; Labajos, F.M.; Trujillano, R.; Romeo, E.; Royo, C.; Monzón, A. Acetylene hydrogenation on Ni-Al-Cr oxide catalysts: the role of added Zn. Appl. Clay Sci. 1998, 13, 363-379.

34. Vora, A.; Riga, A.; Dollimore, D.; Alexander, K.S. Thermal stability of folic acid. Thermochim. Acta 2002, 392, 209-220.

35. Choi, S.J.; Oh, J.M.; Park, T.; Choy, J.H. Cellular toxicity of inorganic hydroxide nanoparticles. J. Nanosci. Nanotechnol. 2007, 7, 4017-4020.

36. Choi, S.J.; Oh, J.M.; Choy, J.H. Safety aspect of inorganic layered nanoparticles: Size-dependency in vitro and in vivo. J. Nanosci. Nanotechnol. 2008, 8, 5297-5301.

37. Choi, S.J.; Choy, J.H. Layered double hydroxide nanoparticles as target-specific delivery carriers: Uptake mechanism and toxicity. Nanomed. UK 2011, 6, 803-814.

38. Kim, T.H.; Heo, I.; Paek, S.M.; Park, C.B.; Choi, A.J. Layered metal hydroxides containing calcium and their structural analysis. Bull. Korean Chem. Soc. 2012, 33, 1845-1850.

(C) 2014 by the authors; licensee MDPI, Basel, Switzerland. This article is an open access article distributed under the terms and conditions of the Creative Commons Attribution license (http://creativecommons.org/licenses/by/4.0/). 